\title{
The LRG Software for liquefaction mitigation planning and decision
}

\section{support}

\author{
Abdelghani Meslem, Håvard Iversen, Dominik Lang, Tina Kaschwich, Linn Sir Drange \\ NORSAR, Norway
}

Keith Jones

Anglia Ruskin Univeristy, United Kingdom

Contacting author: abdelghani.meslem@norsar.no

\begin{abstract}
LIQUEFACT Reference Guide (LRG) software is one of the main products of the LIQUEFACT, a multidisciplinary project funded under the European Commission's Horizon 2020 framework program. The software, which incorporates both data and methodologies collected and elaborated in the project's various work packages, has been developed for liquefaction mitigation planning and decision support, able to estimate and predict the likely consequences of Earthquake-Induced Liquefaction Disaster (EILD) to the most vulnerable region of Europe. In contrast to other seismic risk assessment software tools, the LRG software is targeting a wider range of user groups with different levels of technical background (urban planners, facility managers, structural and geotechnical engineers, or seismic risk modelers) as well as requirements. In doing so, the LRG software toolbox shall allow users assessing the liquefaction-related risk as well as assisting them in liquefaction mitigation planning.
\end{abstract}

Keywords: Liquefaction Risk, Liquefaction Mitigation, Assessment/Repair, Facility Management.

\section{Introduction}

One of the key outputs from the LIQUEFACT project, funded under the European Commission's Horizon 2020 framework program, is the LIQUEFACT Reference Guide (LRG) software, a toolbox for liquefaction mitigation planning and decision support, able to estimate and predict the likely consequences of Earthquake-Induced Liquefaction Disaster (EILD) to the most vulnerable region of Europe [1].

The development of the LRG software has been undergoing in two main phases: the first phase of the development process involves reviewing the various methodologies and procedures that are developed and suggested by the LIQUEFACT consortium partners. This activity has also included the examination of various potential challenges and issues in integrating the methodologies and procedures into a software toolbox. This has allowed to establish a common understanding of how the software will be used in practice and define specifications of the data, tools and models to be developed in subsequent work packages in order to ensure their successful integration into the LRG software. 
The second phase of the development process involves the design and development of protocols and modules were the various outputs from the LIQUEFACT consortium partners are integrated into the software toolbox that will provide civil engineers and relevant stakeholders guidance in making informed assessments on the feasibility and cost-benefit of applying certain liquefaction mitigation techniques for a given earthquakeinduced liquefaction threat.

This report provides a description on the development process of the LRG software, illustrating the various steps and activities that have been undertaken in designing and developing an easy-to-use software toolbox that can provide guidance during the building design/assessment and implementation but also during the planning process at local and regional level. The report provides insights on how the various methodologies and different forms of data, provided by the other work packages, have been integrated, and illustrates the interaction between the various protocols of the hazard, risk and mitigation analysis, as well as the concept and the philosophy of analysis process that characterise the software.

This present paper provides a description on the development process of the LRG software, illustrating the various steps and activities that have been undertaken in designing and developing an easy-to-use software toolbox that can provide guidance during the building design/assessment and implementation but also during the planning process at local and regional level. The paper provides insights on how the various methodologies and different forms of data, provided by the other work packages, have been integrated, and illustrates the interaction between the various protocols of the hazard, risk and mitigation analysis, as well as the concept and the philosophy of analysis process that characterise the software.

\section{LRG software processing concept}

Earthquake-induced liquefaction damage assessment is a multi-process analysis that requires different types and forms of input data related to geology and seismology of the site, geotechnical data, and structure-foundation system characteristics of the asset under risk (Table 1). To this end, the LRG software has been designed in a way that EILD assessment is conducted at three independent protocol of analysis to provide more flexibility to the enduser's requirements with respect to the level of analysis to be implemented and type of input data that are available [1].

Table 1. LRG software Concept with respect to the type of analysis and level of data requirement

\begin{tabular}{ll}
\hline Type of Analysis & Data Requirement \\
\hline $\begin{array}{l}\text { hazard analysis - } \\
\text { liquefaction susceptibility } \\
\text { (qualitative analysis) }\end{array}$ & $\begin{array}{l}\text { liquefaction } \\
\text { hazard/susceptibility } \\
\text { map }\end{array}$ \\
\hline $\begin{array}{l}\text { hazard analysis - } \\
\text { probability and ground } \\
\text { deformation (quantitative } \\
\text { analysis) }\end{array}$ & $\begin{array}{l}\text { geological and } \\
\text { geotechnical data }\end{array}$ \\
\hline $\begin{array}{l}\text { EILD risk impact on the } \\
\text { asset }\end{array}$ & $\begin{array}{l}\text { structural characteristics- } \\
\text { related data and } \\
\text { vulnerability models }\end{array}$ \\
\hline $\begin{array}{l}\text { mitigation and cost-benefit } \\
\text { analysis }\end{array}$ & $\begin{array}{l}\text { library of liquefaction } \\
\text { mitigation measures and } \\
\text { cost-benefit data }\end{array}$ \\
\hline
\end{tabular}

The three-independent protocol of analysis implemented in the LRG software are: the protocol for liquefaction hazard analysis, the protocol for risk analysis, and the protocol for mitigation analysis (see Figure 1). At the stage of liquefaction hazard, the end-user can conduct qualitative analyses to identify how likely an asset is susceptible to liquefaction. If the end-user wants to conduct a risk analysis as well, which is aimed to estimate the level of impact of the potential liquefaction threat on the asset and evaluate the performance, then a quantitative analysis of the liquefaction potential is required followed by structural response and damage analysis, and performance evaluation. For the Mitigation Analysis, the end-user can develop a customized mitigation framework based on the outcome of the risk analysis [1]. 


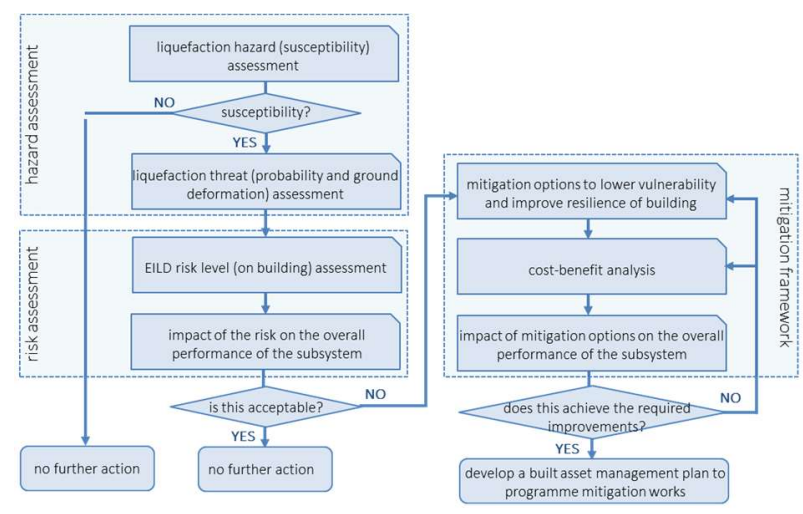

Figure 1. LRG software processing and analysis concept

\subsection{Analysis processes}

The LRG software has the following specifications and characteristics [1]:

\subsubsection{Stage 1: Assess liquefaction susceptibility}

At the stage of the liquefaction susceptibility analysis, the assessment is conducted to identify whether an asset (e.g. individual building/ $\mathrm{Cl}$ asset, portfolio of buildings/distributed infrastructure assets, etc.) is located in a geographical area likely to be affected by an EILD event. The level of hazard is evaluated by considering the probability of an earthquake hazard and the susceptibility of the ground to liquefaction. This process consists in developing a Susceptibility Matrix [2] that relates earthquake characteristic to ground characterization in order to identify the level of hazard of the asset. The level of hazard is classified using qualitative labels ranging from "Very Low" to "Very High" that express the level of likelihood of the ground below the asset to liquefaction for any given earthquake characteristic. This analysis provides asset managers and other stakeholders with an assessment of the range of exposures that their asset(s) is/are likely to be susceptible to.

\subsubsection{Stage 2: Evaluation of the level of liquefaction threat to be correlated with the asset response}

To assess how the built/infrastructure asset is likely to be affected by an EILD event, liquefactioninduced ground deformation is correlated, by using intensity measure such as spectral acceleration $\mathrm{Sa}(\mathrm{T} 1)$, Liquefaction Severity Number (LSN)...etc., with the asset response. This computation can be implemented using various approaches that were developed and integrated into the LRG software, depending on what type of soil profile data are available (CPT, SPT...etc.).

\subsubsection{Stage 3: Impact of the EILD on the built or infrastructure asset}

Through identifying the building/infrastructure typology using an integrated classification system (is likely to be a combination of construction and foundation type), and through the combination with the associated pre-defined vulnerability model (ground shaking and liquefaction fragility curves), the potential level of damage and vulnerability to the ground condition scenarios, identified in stage 2, are evaluated. For asset managers and other stakeholders, the result of this analysis of damage and vulnerability will be provided in form of a classification using qualitative labels ranging from "Very Low" to "Very High" [2].

\subsubsection{Stage 4: Evaluate performance and functionality of the asset}

The overall performance and functionality of the asset is evaluated on a case by case basis using the expert knowledge of the facilities manager and building users to interpret the impact the damage and risk (from Stage 3) will have on functionality and performance. The loss of functionality will be categorised using qualitative labels ranging from "minor non-structural damage" to "major structural damage" with the loss of performance being a further qualitative statement contextualising the impact of the loss of functionality.

\subsubsection{Stage 5: Impact of the EILD on the built or infrastructure asset}

Once the level of loss of performance and functionality of individual building/infrastructure assets and the impact on the resilience of a community following an EILD event has been established, end-users will be directed to develop a customized mitigation measure. Based on the outcomes of the hazard-risk analysis (from Stage 1 to 4), a range of mitigation actions are to be 
identified, and the effect of each on the level of performance of individual buildings/infrastructure assets has to be evaluated. Two types of mitigation actions need to be considered: those that seek to reduce a building/infrastructure asset's vulnerability/increase its resilience; and those that seek to reduce the hazard level. Mitigation options will be ranked according to their impact on the sub-system level and on their contribution to improving overall community resilience.

\subsection{Options and alternatives}

Taking into account the aspects described above, the LRG software is designed and developed to provide up to nine options/alternatives of analysis processing, as illustrated in Figure 2, offering more flexibility to end-users in conducting an assessment with respect to how detailed the input data are, the availability of the data, and what type of assessment and result the end-users want to obtain.

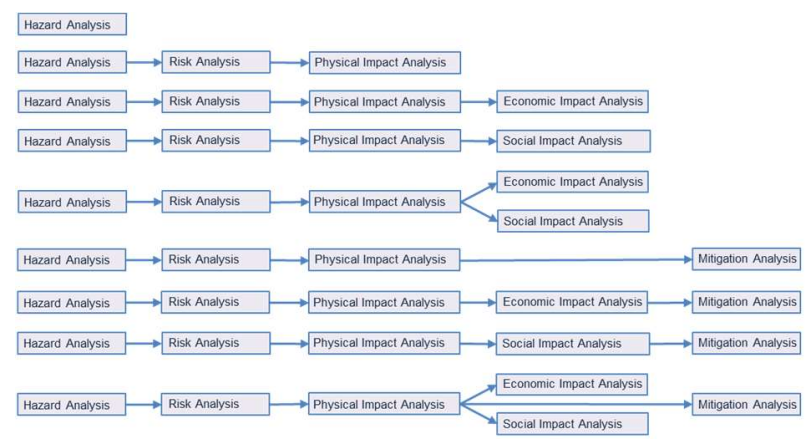

Figure 2. Alternatives offered in the LRG software for EILD related analysis

\section{Technology in the LRG software development}

The LRG software is entirely written in the C++ programming language [3] and is developed exploiting object-oriented methodologies and tools, a number of dependences on open-source libraries, and implementation of a wide set of state-of-the-art algorithms. The aim of the various choices undertaken was to ensure the creation of features that would allow end-users a better flexibility and control in terms of selection of assessment/ analysis procedure to be implemented, how to view the various results of analyses, type of inputs that can be used/accepted by the software and type of outputs that can be obtained from the software allowing an easy reading and understanding for non-technical user (see Figure 3).

The user interface has been developed using $\mathrm{C}++-$ based tools such as Qt [4] which is a crossplatform application framework that is used for developing application software that can be run on various software and hardware platforms with little or no change in the underlying codebase, while still being a native application with native capabilities and speed.

Import of data into the LRG software will be based on tab-separated CSV files or SHAPE files that will be converted to SQLite database files in the project (through a database management system). Results can be exported to CSV or SHAPE, and be generated as 2D grids (e.g. ground shaking or liquefaction hazard maps) through a GIS interactive mapping system.

The LRG software uses Geographic Information Systems (GIS) technology, allowing users to visualize the spatial relationships between various geographic assets or resources for the specific hazard being modeled, a crucial function in the planning process. Open Street Map [5] has been embedded in the Qt for the LRG map module, providing the following features:

- view individual buildings;

- view street names and other labels;

- allowing the overlay of input data (e.g. data on buildings, liquefaction profiles and ground shaking maps) on the LRG map;

- Hide/show overlays of various types;

- obtain a street address from a location (latitude, longitude);

- obtain a location (latitude, longitude) from a street address;

- Click on markers (building, liquefaction profile);

- Zoom in and out, and translate the map;

Specify geographical region; and many more features.... 


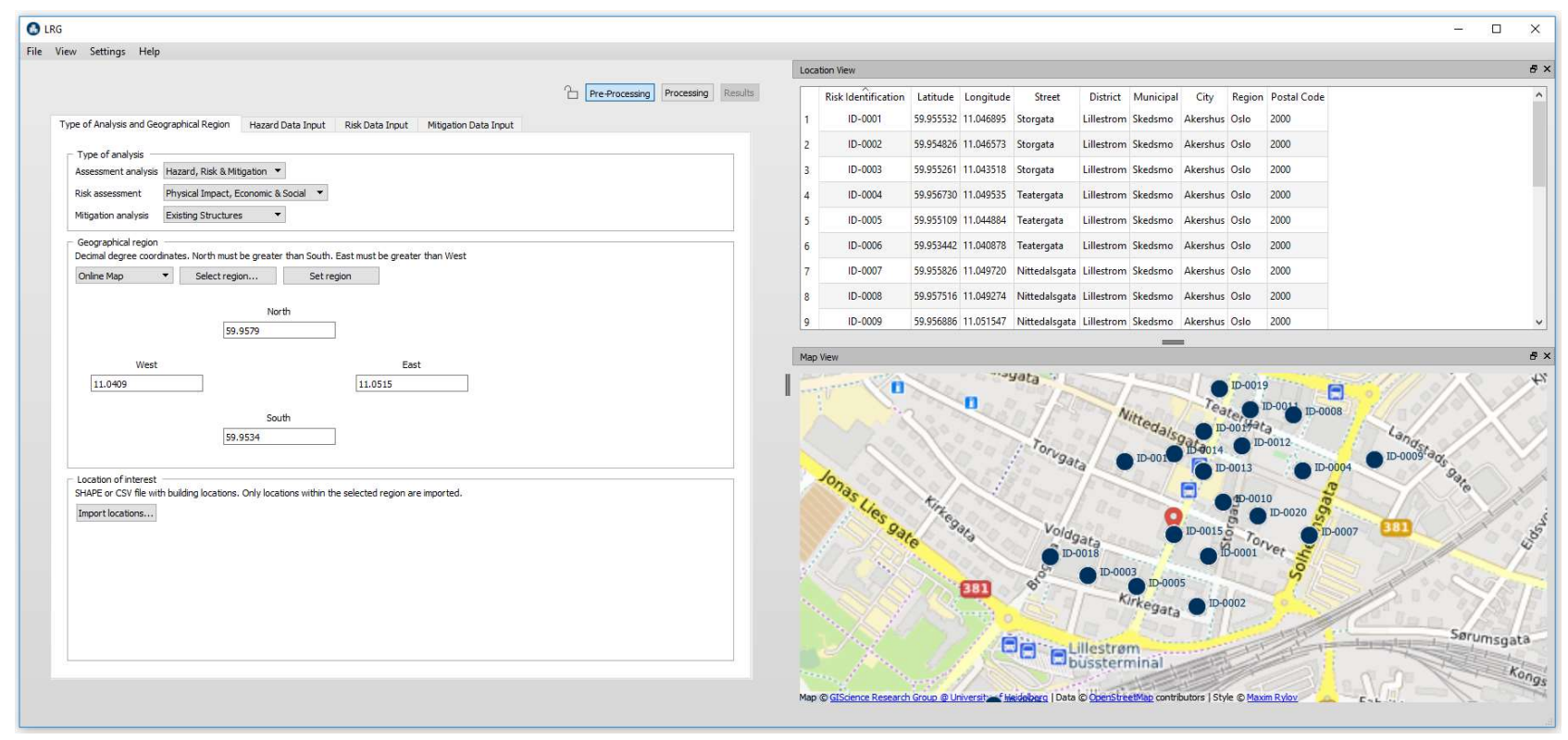

Figure 3. $L R G$ Software - graphical user interface

\section{Software protocols and modules}

The LRG software computes and analyses earthquake-induced liquefaction damage, the performance and impact for a specific affected property portfolio. The program can use seismic hazard maps (e.g. PSHA based for given return periods) or scenarios as earthquake load inputs, and liquefaction hazard map. The Software consists of three protocols: Liquefaction Hazard Analysis Protocol, Risk Analysis Protocol, and Mitigation Analysis Protocol. Each protocol consists of an Input and a Results Module.

\subsection{Protocol for liquefaction hazard analysis}

The development of the Liquefaction Hazard Analysis Protocol in the LRG software has been conducted by the design and incorporation of the followings:

- Sub-Protocol with modules for the evaluation of Liquefaction Potential (i.e. susceptibility and probability of liquefaction);

- Sub-Protocol with modules for the evaluation of Liquefaction Demand.

The evaluation of potential liquefaction is a twostep process that involves: (a) the evaluation of liquefaction susceptibility of the soil at a specific location; (b) the evaluation of liquefaction probability for a given level of amplitude and duration of ground shaking [6].

Liquefaction demand expresses the liquefactioninduced ground deformation beneath an asset (individual building $/ \mathrm{Cl}$ asset, portfolio of buildings/distributed infrastructure assets, etc.). In the LRG software, the sub-protocol for liquefaction demand analysis is implemented by incorporating methodologies and the required parameters that allow the computation of ground deformation in terms of intensity measure such as $\mathrm{Sa}(\mathrm{T} 1), \mathrm{LSN}$, as well as in terms of modes of permanent ground displacement [6].

\subsection{Protocol for risk analysis}

The development of the Liquefaction Risk Analysis Protocol in the LRG software has been conducted by the design and incorporation of the followings:

- Sub-Protocol with modules for building response analysis to a defined liquefaction demand $(\mathrm{Sa}(\mathrm{T} 1), \mathrm{LSN}$, mode of liquefaction ground deformation, etc.), and evaluation of the various mechanisms of structural deformation;

- Sub-Protocol with modules for the ground shaking and liquefaction vulnerability models, 
and evaluation of structure performance to a defined liquefaction demand.

The Sub-Protocol for structure response to a defined liquefaction ground deformation is a twostep process that involves: (a) definition of structure-foundation system; (b) prediction of structural deformation mechanisms/response. The Sub-Protocol for asset damage and performance evaluation is a two-step process that involves: (a) incorporation of fragility model for the defined asset class; and (b) methodologies for the evaluation of damage and the overall performance of the asset [7].

\subsection{Protocol for mitigation measure selection}

In the LRG software, the protocol for mitigation analysis is designed to include: a process for selecting an appropriate mitigation measure considering the actual in-site condition, and a process for cost-benefit analysis and socioeconomic impact.

Liquefaction mitigation measures are categorized into two main groups: (a) measures and techniques applicable in a situation of an existing structure/infrastructures; and (b) measures and techniques applicable in a situation of a free-field condition site. The Protocol for Mitigation Analysis will include a module where end users can input site-specific information on the respective area under investigation to determine appropriate mitigation measures and present them to the user in a concise and helpful way.

The protocol for mitigation analysis also incorporates a cost-benefit analysis that is used to approximately estimate the cost of each mitigation technique.

\section{Conclusions}

This paper provides a description of the LRG software development process that has been undergoing through various development and improvement. The aim is to come-up with an easy-to use software application toolbox, wherein civil engineers and other relevant stakeholders involved in the design and implementation of a structure or infrastructure is guided to make informed assessments on the feasibility and costbenefit of applying certain liquefaction mitigation techniques within specific European regions. The LRG software is designed to be applied for an individual level (individual structure or infrastructure) and for region/city level (i.e. in an urban area, GIS-based outputs) with procedures for calculating socio-economic impacts and proposing risk reduction and resilience improvement strategies.

The various parts of the LRG software development presented in this paper are still work in progress which will be updated and amended throughout the duration of the LIQUEFACT project.

\section{Acknowledgements}

This Project has received funding from the European Union's Horizon 2020 research and innovation programme under grant agreement No. 700748.

\section{References}

[1] Meslem, A., Lang, D., and Iversen, H. (2017). Deliverable D6.1 LRG Software Toolbox for Liquefaction Mitigation Planning and Decision Support (version1). LIQUEFACT Project.

[2] Bartolucci, A. and Jones, K. (2016). Deliverable D1.4 Detailed user requirements and research output protocols for the LIQUEFACT Reference Guide. LIQUEFACT Project

[3] Stroustrup, S. (2012) The C++ Programming Language, 4th edition, ISO/IEC 14882:2011.

[4] Rischplater, R. (2014) Application Development with Qt Creator, Second Edition, PACKT publishing, ISBN-13: 9781784398675.

[5] Bennet, J. (2010) OpenStreetMap, Packt publishing, Birmingham.

[6] Lai, C.G., Meisina, C., Persichillo, P., Famà, A., Bozzoni, F. and Cosentini, R. (2017). Deliverable D2.2 GIS platform including data for liquefaction hazard assessment in Europe (version 1). LIQUEFACT Project. 
[7] Viana da Fonseca, A., Millen, M., GómezMartinez, F., Romão, X., Quintero, J., Gómez, F., Costa, P., Rios, S., Kosič, M., Dolšek, M., Logar, J., Oztoprak, S., Bozbey, I., Kelesoglu, K., Ozcep, F., Flora, A., Rasulo, A., Modoni, G. and Croce, P. (2017). Deliverable D3.1 State of the art review of numerical modelling strategies to simulate liquefaction-induced structural damage and of uncertain/random factors on the behaviour of liquefiable soils. LIQUEFACT Project. 